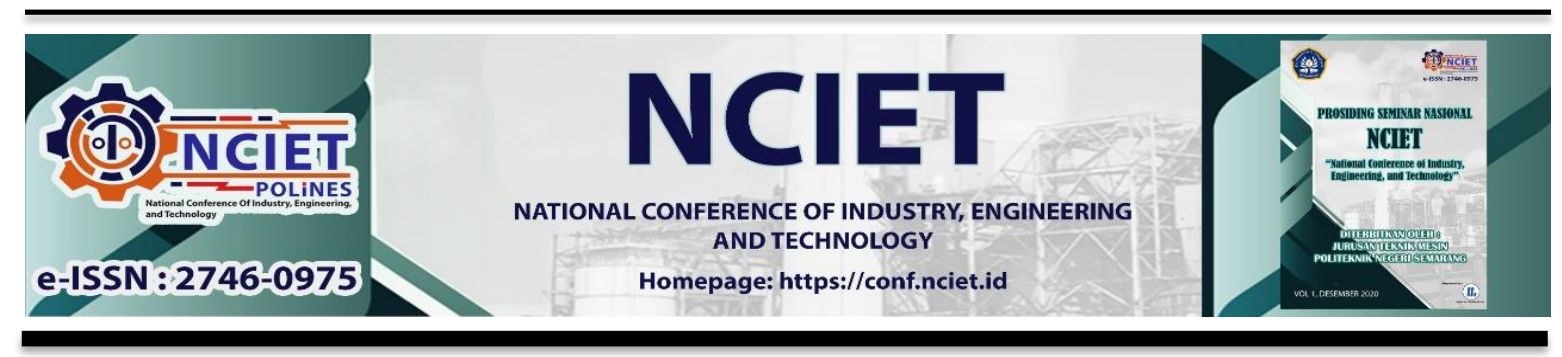

Prosiding Seminar Nasional NCIET Vol.1 (2020) A29-A36

$1^{\text {st }}$ National Conference of Industry, Engineering and Technology 2020, Semarang, Indonesia.

\title{
APLIKASI SISTEM SENTRIFUGAL PADA ALAT PERONTOK LADA DAN PELUKA KULIT LADA
}

\author{
Sugianto*, Hasdiansah \\ Jurusan Teknik Mesin, Politeknik Manufaktur Negeri Bangka Belitung \\ Jl. Timah Raya Kawasan Industri Air Kantung, Sungailiat, 33211 \\ *E-mail: sugianto@polman-babel.ac.id
}

\begin{abstract}
Abstrak
Secara tradisional perendaman lada dalam air mengalir dilakukan selama 12-14 hari. Selain waktu yang cukup lama, juga berpotensi terkontaminasi bakteri E Coli. Proses dapat di kondisikan pada air tidak mengalir dengan tiga metoda; semi mekanik, enzimatik, maupun gabungan dari duanya. Proses perendaman kemudian dikupas dengan mesin mempercepat proses menjadi 5 hari. Sedangkan perendaman disertai enzimatik proses mempercepat hingga 3-5 hari. Metode yang sedang dikembangkan adalah melukai kulit lada sebelum direndam untuk mempercepat proses pembusukan. Tanpa proses pengupasan kulit, pelukaan dan penambahan enzim mempersingkat perendaman menjadi 5 hari. Namun proses pelukaan masih dilakukan secara manual dengan balok kayu.Mekanisasi proses pelukaan kulit lada dalam penelitian ini dilakukan dengan pendekatan kuantitatif untuk mendapatkan kesimpulan yang bersifat kualitatif. Penelitian divokuskan pada mekanisme penggilas yang di konstruksikan dalam bentuk pasangan tabung kerut bersirip tidak bergerak (stator) dan bergerak (rotor). Penelitian mengamati pengaruh konstruksi sirip terhadap efektivitas dan efisiensi. Dari percobaan diketahui bahwa kemiringan sirip berpengaruh terhadap kecepatan proses perontokan dan kemampuan melukai kulit lada. Sirip helix mampu merontokan $\approx 96 \%$ dan lebih cepat namun belum mampu memberikan luka pada kulit. Kontruksi sirip miring merontokkan hampir $100 \%$ dan dapat melukai pada kulit walaupun masih sekitar $\approx 2 \%$.
\end{abstract}

Kata Kunci: lada, perontokkan lada; kulit lada; perendaman lada; proses enzimatik

\section{PENDAHULUAN}

Secara turun temurun proses pengolahan lada putih di Bangka Belitung dilakukan dengan memasukkan lada ke dalam karung kemudian direndam dalam air mengalir di kolong atau sungai selama 12 sampai 14 hari. Tujuan perendaman agar terjadi pembusukan kulit luar sehingga kulit buah lada mudah dilepaskan dari bijinya untuk selanjutnya dikeringkan pada terik sinar matahari. 
Ketersediaan air bersih untuk perendaman sangat berpengaruh pada kualitas lada. Semakin sedikitnya sumber air bersih disekitar perkebunan berdampak pada rendahnya mutu lada. Berdasarkan hasil penelitian ditemukan beberapa sampel lada putih yang diperoleh dari petani dan eksportir di Bangka positif mengandung bakteri E coli (Sri Usmiati, 2006) dan (Muhammad Syakir, 2017).

Mengacu pada Peraturan Menteri Pertanian No. 55 tahun 2012, Rendahnya mutu tersebut disebabkan adanya pencemaran mikroorganisme, bahan asing, kadar air dan kadar minyak yang tidak memenuhi syarat. Pencemaran oleh mikroorganisme dan bahan-bahan asing tersebut sebagian besar terjadi selama penanganan seperti perendaman, pemisahan kulit maupun pada proses pengeringan.

Untuk menjaga kualitas lada Bangka Belitung, Gubernur Erzaldi Rosman Djohan juga telah menetapkan syarat bebas bakteri salmonella dan E.coli sebelum lada diperdagangkan (Ferdiansyah, 2020). Oleh karena itu perlu ada upaya mengintegrasikan teknologi dalam proses pengolahan lada paska panen terutama pada proses perendaman agar terbebas dari pencemaran bakteri.

Proses pengolahan lada putih dapat dilakukan dengan tiga metoda yaitu semi mekanik, enzimatik, maupun gabungan dari dua metode tersebut. Semi mekanik yaitu proses pengupasan setelah direndam selama beberapa hari. Perlakukan semi mekanik dengan perendaman pada wadah yang dikombinasikan dengan penggantian air rendaman mempercepat proses menjadi 5 hari (Muhammad Syakir, 2017). Selain itu proses semi mekanik yang dilalukan disertai proses enzimatik mempercepat perendaman perendaman menjadi lima hari (Ashari M.F, 2014) dan tiga hari (Ibrahim M.D, 2014).

Saat ini beberapa metode yang masih terus dikembangkan adalah dengan melukai kulit lada sebelum direndam dengan tujuan agar luka yang terjadi pada kulit lada akan mempercepat proses perendaman. Dalam kesimpulan laporan skripsi mahasiswa UBB, proses pelukaan dan penambahan enzim mempersingkat perendaman menjadi 5 hari (Julian, 2017), (Rapi, 2018) dan (Pricilla, 2019). Namun demikian proses pelukaan masih dilakukan secara manual dengan balok kayu (Kamila, 2019). Berdasarkan kondisi tersebut, penelitian ini dilakukan dengan rumusan masalah tentang bagaimana sistem mekanisasi proses perontokkan dan pelukaan kulit lada agar dapat dilakukan secara efektif dan efisien. Dengan penelitian ini diharapkan dapat memberikan kontribusi dibidang teknologi tentang mekanisme proses perontokan dan pelukaan kulit lada dengan mesin yang nantinya dapat dimanfaatkan untuk meningkatkan kualitas lada putih. 


\section{METODE PENELITIAN}

Proses penelitian dilakukan di Politeknik Negeri Bangka Belitung, dimulai dengan merancang alat perontok dan peluka biji lada. Mesin dioperasikan dengan motor bakar 6,5 HP merek Falcon langsung tanpa sistem transmisi tambahan. Sebagian besar komponen mesin akan dibuat menggunakan mesin 3D printer berbahan PLA dengan rangka terbuat dari profil baja persegi $40 \mathrm{~mm} \times 40 \mathrm{~mm}$.

Bahan uji adalah lada siap panen berwarna hijau agak kekuningan yang dipatik satu hari sebelum pengujian dengan jumlah sampel $4 \mathrm{~kg}$ setiap pengujian. Pengujian bertujuan untuk mengukur performa waktu proses, kemampuan merontokkan, kemampuan memberikan luka pada kulit lada. Variabel peubah yang akan diamati adalah bentuk konstruksi penggilas buah lada dan kecepatan putaran mesin.
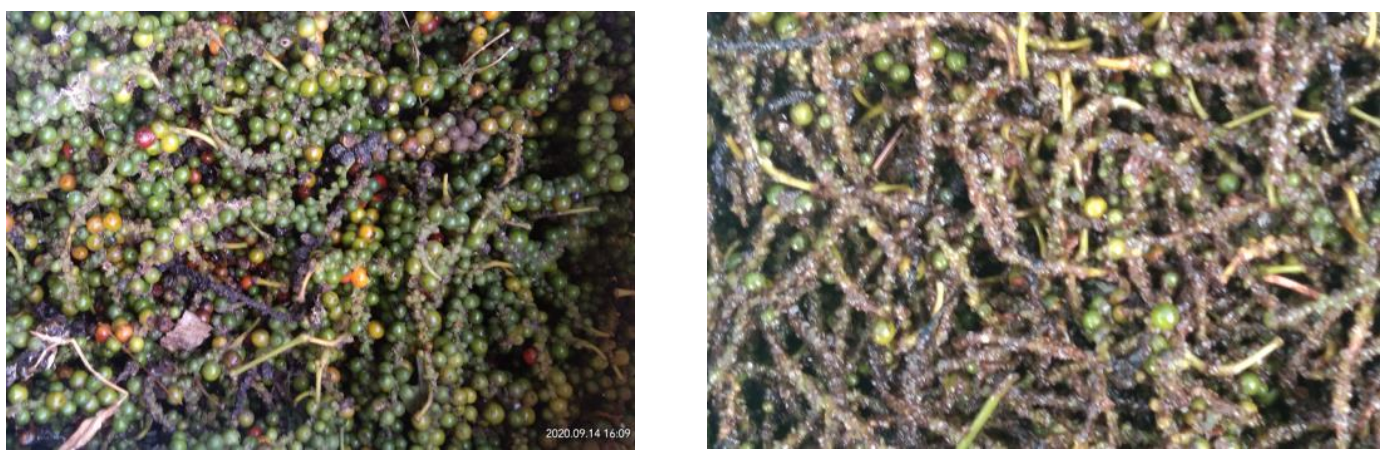

Gambar 1. Lada yang akan di proses (kiri) dan tangkai lada setelah perontokkan (kanan)

Secara umum mesin dibuat dengan dimensi $70 \mathrm{~cm}$ x $65 \mathrm{~cm}$ x $50 \mathrm{~cm}$ yang memiliki komponen utama dari mesin terdiri dari;

1. Rotor berbentuk kerucut yang bagian dalamnya dilengkapi dengan sirip sebagai penggilas untuk merontokkan dan memberikan gesekan agar melukai buah lada.

2. Stator berbentuk kerucut yang memiliki sirip pada bagian luar untuk menghambat gerak buah lada saat terbawa oleh rotor.

3. Konveyor berbentuk ulir yang berfungsi untuk membawa lada agar masuk ke celah diantara rotor dan stator.

Bagian yang akan diamati pada penelitian ini adalah bentuk sirip pada rotor dan pengaruhnya terhadap performa yang diharapkan. Secara umum sirip konstruksikan menempel pada bagai dalam kerucut dengan sudut pendakian yang berbeda. Tipe pertama 
dikonstruksi dengan sudut pendakian yang tinggi selanjutnya disebut sirip tipe miring. Tipe kedua sirip dengan sudut pendakian rendah yang selanjutnya disebut tipe helix.

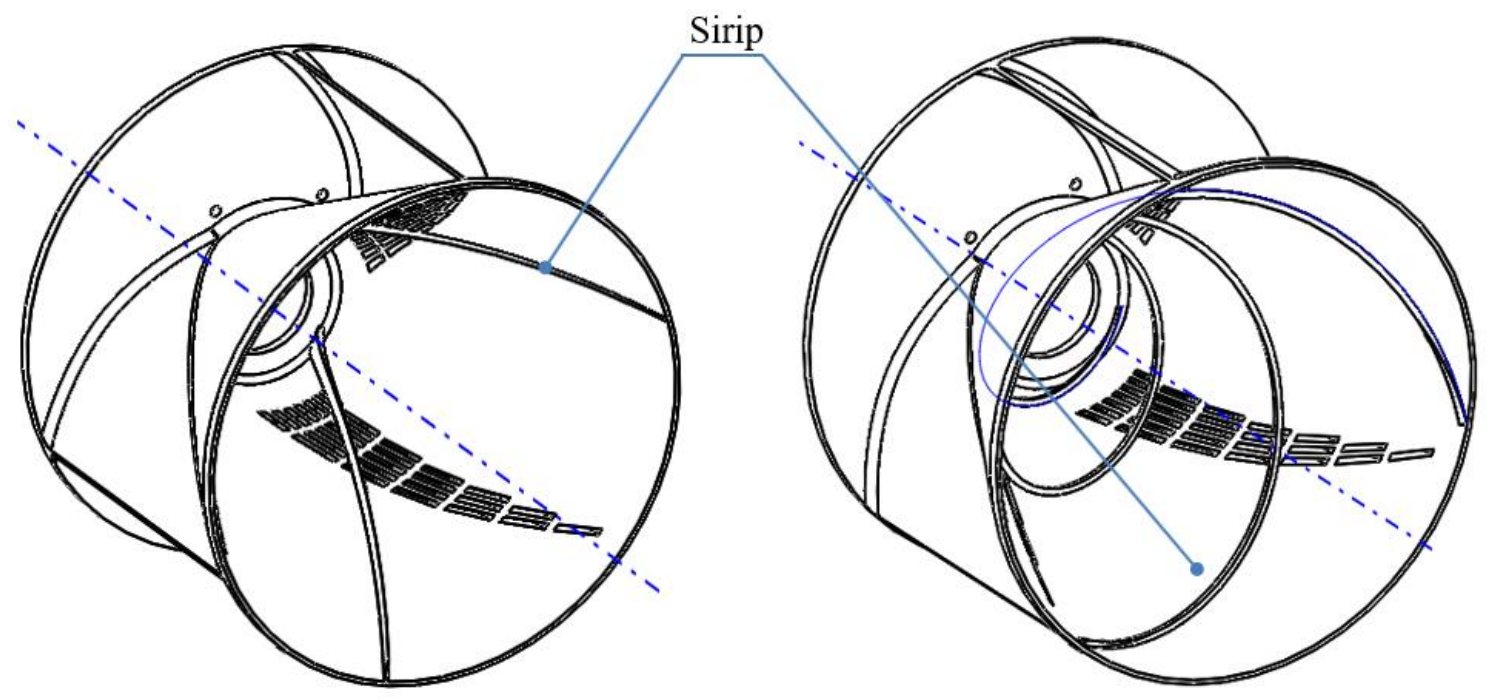

Gambar 2. Rotor tipe miring (kiri) dan rotor tipe helix (kanan)
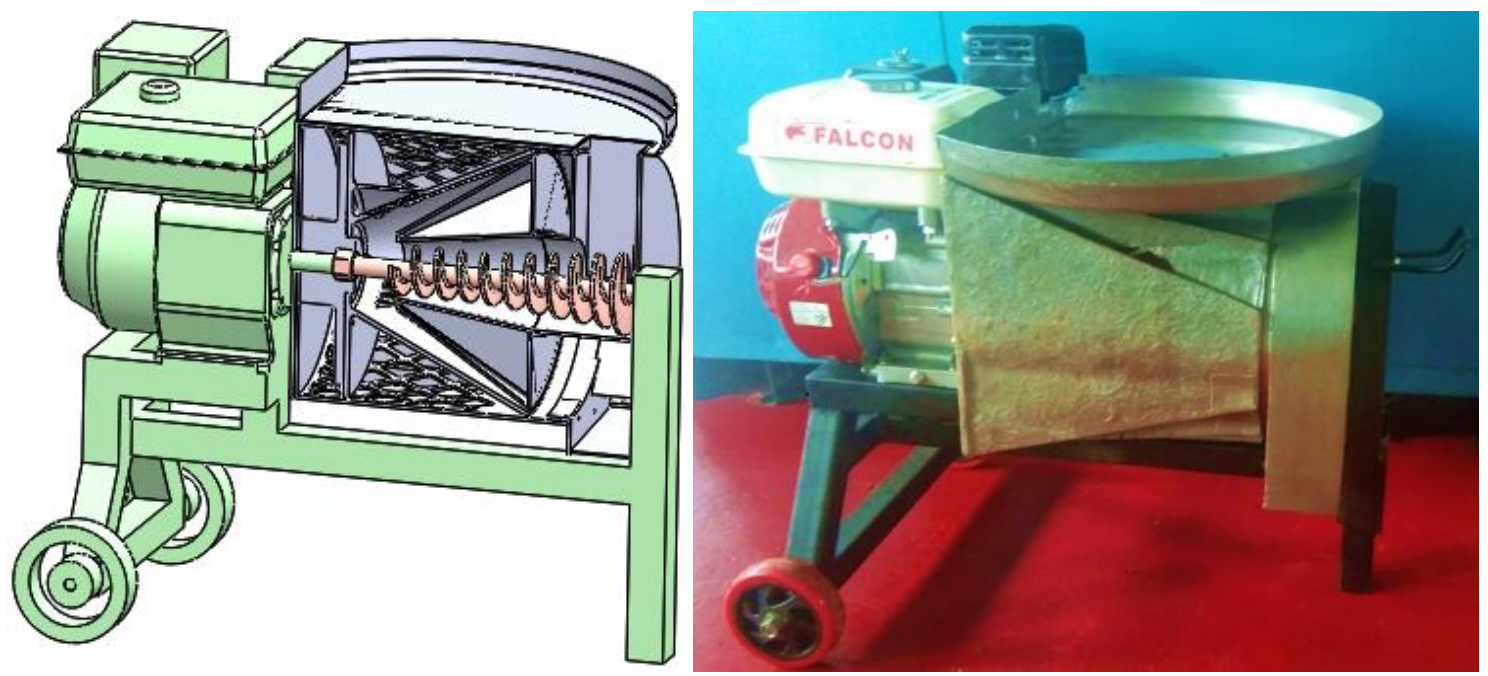

Gambar 2. Desain alat (kiri) dan Prototipe alat (kanan).

\section{HASIL DAN PEMBAHASAN}

Pada percobaan menggunakan rotor tipe miring dengan bahan uji berupa lada yang masih bertangkai sebanyak $4 \mathrm{~kg}$. Proses pengujian dilakukan dengan memvariasikan kecepatan putaran mesin menjadi 3 yaitu rendah, sedang dan tinggi (dilakukan dengan mengatur tali gas pada motor). Hasil pengujian dapat dilihat pada tabel 1 dan gambar 3 . 
Dari percobaan tersebut diperoleh data kapasitas rata-rata adalah $71 \mathrm{~kg} / \mathrm{jam}$ dengan tingkat kerontokan $\approx 99 \%$ namun kemampuna mesin untuk melukai kulit lada masih sangat rendah.

Tabel 1. Proses perontokan dan pelukaan dengan rotor tipe miring

\begin{tabular}{|l|c|c|c|c|}
\hline \multicolumn{1}{|c|}{ Bahan } & $\begin{array}{c}\text { Putaran } \\
\text { rendah }\end{array}$ & $\begin{array}{c}\text { Putaran } \\
\text { sedang }\end{array}$ & $\begin{array}{c}\text { Putaran } \\
\text { tinggi }\end{array}$ & Rerata \\
\hline Lada pasca petik $(\mathrm{g})$ & 4000 & 4000 & 4000 & 4000 \\
\hline Kinerja perontokkan $(\approx \%)$ & $98,0 \%$ & $99,0 \%$ & $100,0 \%$ & $99,0 \%$ \\
\hline Kinerja pelukaan kulit lada $(\approx \%)$ & $0 \%$ & $1 \%$ & $2 \%$ & $1 \%$ \\
\hline Waktu proses ( $\approx$ menit) & 3,8 & 3,4 & 3,0 & 3,40 \\
\hline Kapasitas proses $(\approx \mathrm{kg} / \mathrm{h})$ & 63 & 71 & 80 & 71 \\
\hline
\end{tabular}
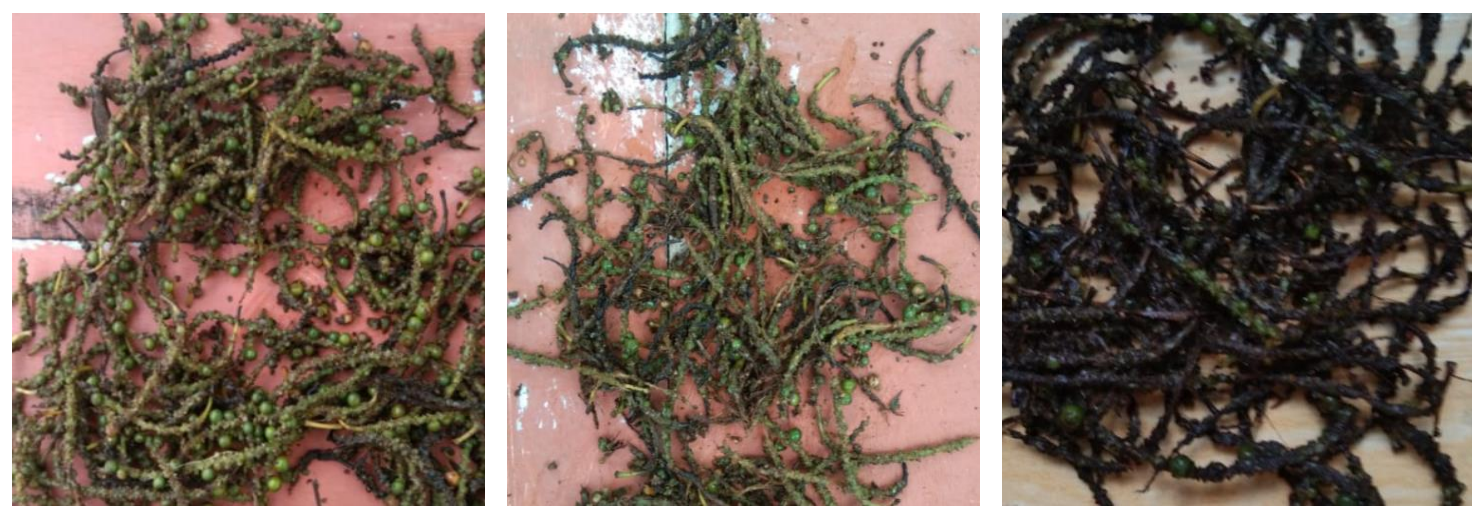

Gambar 3. Sisa tangkai lada putaran rendah, sedang dan tinggi (dari kiri).
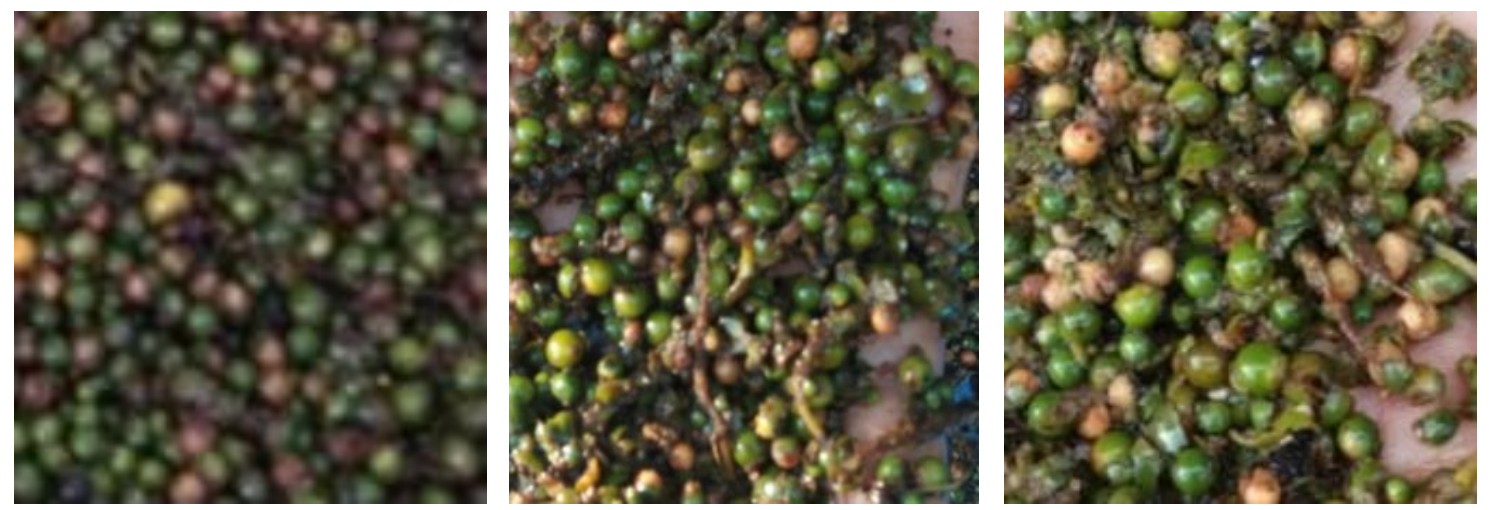

Gambar 4. Luka kulit lada putaran rendah, sedang dan tinggi (dari kiri).

Percobaan dilakukan menggunakan tipe rotor helix dengan bahan uji adalah lada yang masih bertangkai sebanyak 4kg. Proses pengujian dilakukan pada kecepatan putaran mesin sedang disertai penambahkan air mengalir melewati saluran masuk dengan debit sekitar 0,75 liter/menit. Dari percobaan tersebut diperoleh data seperti pada tabel 2 dan gambar 5 . Dari percobaan tersebut diperoleh data kapasitas rata-rata adalah $94 \mathrm{~kg} / \mathrm{jam}$ dengan tingkat kerontokan $\approx 96 \%$ namun mesin belum mampu melukai kulit lada. 
Tabel 2. Proses perontokan dan pelukaan dengan rotor tipe helix

\begin{tabular}{|c|c|c|c|c|}
\hline Bahan & \multicolumn{2}{|c|}{$\begin{array}{l}\text { Putaran } \\
\text { sedang }\end{array}$} & $\begin{array}{l}\text { Tanpa } \\
\text { proses }\end{array}$ & Rerata \\
\hline Lada pasca petik (kg) & 4000 & 4000 & 4000 & 4000 \\
\hline Kinerja perontokkan $(\approx \%)$ & $97,0 \%$ & $95,0 \%$ & - & $96,0 \%$ \\
\hline Kinerja pelukaan kulit lada $(\approx \%)$ & $0 \%$ & $0 \%$ & - & $0 \%$ \\
\hline 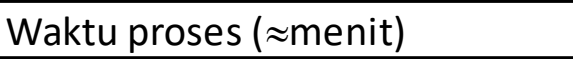 & 2,7 & 2,4 & - & 2,55 \\
\hline Kapasitas proses ( $\approx \mathrm{kg} / \mathrm{h})$ & 89 & 100 & - & 94 \\
\hline
\end{tabular}
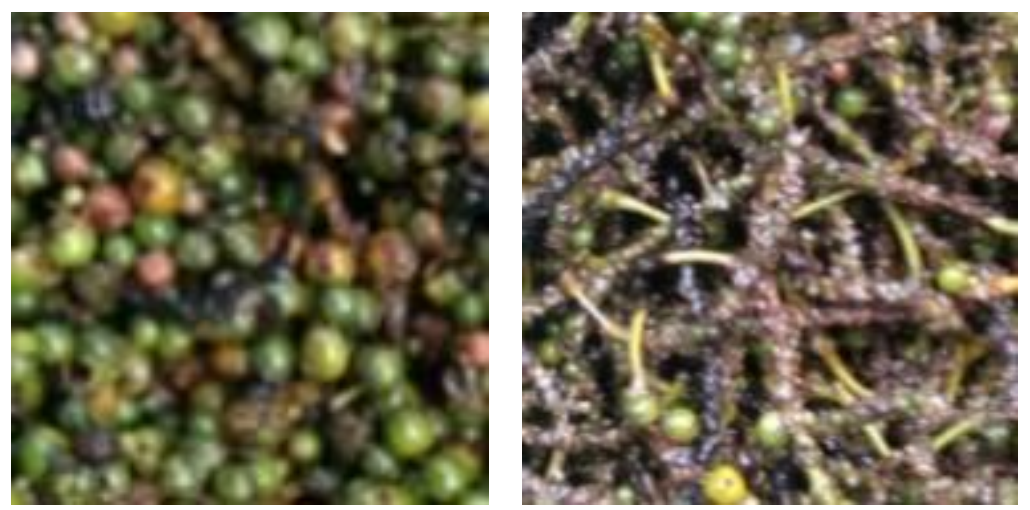

Gambar 5. Hasil perontokan dan sisal tangkai lada.

Dari dua proses percobaan tersebut dapat dilihat bahwa kapasitas mesin dipengaruhi oleh tipe sirip pada rotor. Rotor dengan tipe helix mampu melakukan proses lebih cepat, namun kemampuan dalam merontokkan dan melukai buah kurang baik. Kondisi ini diyakini karena kemiringan sirip yang rendah memungkinkan terjadinya gaya dorong yang lebih besar sehingga lada lebih cepat keluar dari mesin. Oleh karena itu semakin cepat buah keluar dari mesin, semakin sedikit waktu terjadinya gesekan antara buah dengan buah dan antara buah dengan sirip lebih yang pada akhirnya berpengaruh pada kemampuan merontokkan dan melukai kulit buah.

Selain itu penambahan air saat proses juga diyakini berpengaruh terkemampuan merontokkan dan melukai kulit lada. Proses tanpa air menyebabkan kerapatan masa lada didalam ruang perontokan menjadi lebih tinggi karena serpihan yang dihasilkan saat proses menjadi semacam lumpur seperti gambar 6 dan sulit kelular. Sebaliknya dengan penambahan air, serpihan yang terbentuk lebih mudah bergerak keluar sehingga tidak 
menghambat pergerakan lada selama terjadi proses. Selain itu dengan tanpa air, kemungkinan terjadi proses penggilasan yang menyebabkan buah pecah.

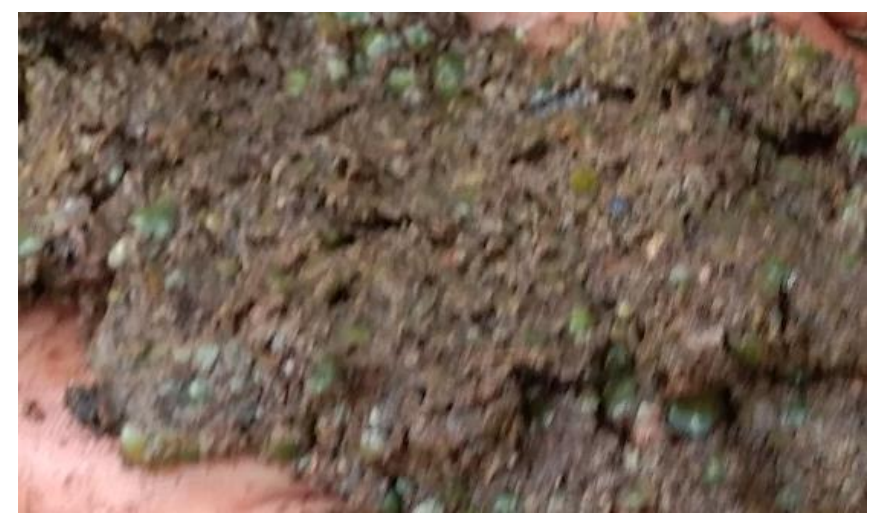

Gambar 5. Hasil perontokan dan sisal tangkai lada.

Dari tabel 3, lada kering hasil proses mesin ini mengakibatkan kerugian yang disebabkan buat pecah dan hancur saat proses maupun retak sehingga rusak saat direndak . Tingkat efisiensi lada kering yang diproses dengan dua tipe rotor ini baru mencapai sekitar $90-92 \%$.

Tabel 3. Rerata hasil lada putih kering

\begin{tabular}{|l|c|c|c|}
\hline \multicolumn{1}{|c|}{ Perlakuan } & $\begin{array}{c}\text { Rotor } \\
\text { Miring }\end{array}$ & $\begin{array}{c}\text { Rotor } \\
\text { Helix }\end{array}$ & $\begin{array}{c}\text { Tanpa } \\
\text { proses }\end{array}$ \\
\hline Lada segar paska petik * & 4000 & 4000 & 4000 \\
\hline Lada kering (gr) & 385 & 391 & 426 \\
\hline Lada sisa dari tangkai & - & 24 & - \\
\hline
\end{tabular}

* lada tidak satu varietas

\section{KESIMPULAN}

Berdasarkan hasil percobaan yang telah dilakukan dapat disimpulkan beberapa hal yaitu;

1. Konstruksi mesin/alat perontok lada dengan sistem sentrifugal pada posisi sumbu horizontal dapat berfungsi dengan baik.

2. Tingkat kerontokan buah dari tanggai baik pada putaran rendah sampai tinggi dan dengan tipe sirip miring serta helix hampir mencapai $100 \%$

3. Pelukaan kulit buah belum efektif baik dengan tipe sirip miring maupun helix.

4. Walaupun sangat sedit masih terlihat ada lada yang pecah saat dirontokkan menggunakan mesin.

Untuk memperbaiki fungsi masin perontok dan peluka kulit lada perlu dilakukan hal-hal sebagai berikut; 
1. Memperbaiki sistem rotor sehingga keberadaan lada didalam mesin menjadi lebih lama.

2. Memodifikasi bentuk sirp meminimalkan tumbukan pada lada saat mesin berputar.

\section{DAFTAR PUSTAKA}

Ashari M.F, I. M. (2014). Accelerated Production Of White Pepper Using Integrated Mechanical And Enzimatic Solution In An Outomated Machine. Tran Tech Publications, 572, 304-307.

Ferdiansyah, R. (2020, Agustus 06). Pemprov Babel Investasi Rp2 Miliar Untuk Kualitas Lada. Diambil Kembali Dari Media Indonesia: Https://Mediaindonesia.Com/Read/Detail/334370-Pemprov-Babel-Investasi-Rp2Miliar-Untuk-Kualitas-Lada

Ibrahim M.D, I. N. (2014). Durabel Hybrid-Powered White Pepper Retting Machine Integrated With Crude Enzimatic Solusion. Jurnal Of Applied Sciense And Agriculture, 9(15), 6-13.

Julian, Z. (2017). Peran MOL Bonggol Pisang (Musa Sp) Dan Perlukaan Mekanis Dalam Mempercepat Pengupasan Kulit Buah Lada Dan Meningkatkan Kualitas Lada Putih ( Piper Nigrum L.) [Skripsi]. Balunijuk: Universitas Bangka Belitung.

Kamila, R. K. (2019). Pengaruh Penundaan Waktu Perendaman Dan Pelukaan Mekanis Terhadap Kualitas Lada Putih Muntok. Jurnal Bioindustri, 214-228.

Muhammad Syakir, T. H. (2017). Karakteristik Mutu Lada Putih Butiran Dan Bubuk Yang Dihasilkan Melalui Pengolahan Semi Mekanis Di Tingkat Petani. Jurnal Penelitian Pascapanen Pertanian, 14(3), 134 - 143.

Pricilla, S. (2019). Percepatan Waktu Perendaman Buah Lada Dengan Pelukaan Mekanis Dan Penambahan Mikroorganisme Lokal (Mol) Jeruk [Skripsi]. Balunijuk: Universitas Bangka Belitung.

Rapi, M. (2018). Optimalisasi Waktu Perendaman Buah Lada (Muntok White Pepper L.) Dengan Perlukaan Mekanis Dan Penambahan Daun Pepaya (Carica Papaya L)[Skripsi]. Balunijuk: Universitas Bangka Belitung.

Sri Usmiati, N. N. (2006). Pengupasan Kulit Buah Lada Dengan Enzim Pektinase. Jurnal Littri, 12( 2), 80-86. 